\title{
METRO LINE ON ACCESS TO ISTANBUL AIRPORT AND SIMULATION STUDY OF THE COVID-19 EFFECT
}

\section{DOI: 10.17261/Pressacademia.2020.1278}

RJBM- V.7-ISS.3-2020(3)-p.149-156

Mevlut Uzulmez ${ }^{1}$, Savas S. Ates ${ }^{2}$

${ }^{1}$ Erciyes University, Faculty of Aeronautics and Astronautics, Kayseri, Turkey. mevlutuzulmez@erciyes.edu.tr, ORCID: 0000-0002-4606-7468

${ }^{2}$ Eskisehir Technical University, Faculty of Aeronautics and Astronautics, Eskisehir, Turkey. ssates@eskisehir.edu.tr, ORCID: 0000-0003-2462-0039

$\begin{array}{ll}\text { Date Received: July 9, } 2020 & \text { Date Accepted: August 29, } 2020\end{array}$

\section{To cite this document}

Uzulmez M., Ates S.S., (2020). Metro line on access to Istanbul airport and simulation study of the covid-19 effect. Research Journal of Business and Management (RJBM), V.7(3), p.149-156.

Permanent link to this document: http://doi.org/10.17261/Pressacademia.2020.1278

Copyright: Published by PressAcademia and limited licensed re-use rights only.

\section{ABSTRACT}

Purpose- It has increased the demand for air transport in the medium and long distance for about two and a half times in Turkey, as in all the world, over the last decade. This increase is for the city of Istanbul in which hosting such a rate of $50 \%$ of air traffic in Turkey has brought the need for a new airport. The first phase of Istanbul Airport (IST-LTFM), that is planned to meet the increasing air transport demand in Istanbul and to increase the existing passenger and cargo carrying capacity, was completed in October 2018. Transportation to Istanbul Airport, which is located further away from the places where the settlement is dense, has gained importance due to its location. Since currently only highway transportation is available, it is planned to provide transportation to the airport by rail and seaways. In the first part of the research, the literature integration with other transportation modes, airport integration and airport access options are viewed. In this context, the information of integration between upcoming rail systems and İstanbul Airport have been obtained from secondary data sources.

Methodology- In the second part of the study, the estimated number of passengers at Istanbul Airport in 2021 and the effects of the COVID19 crisis on the forecasts have been evaluated. In the practice part of the research, through a computer-aided simulation program, the rate of GHYMETRO project's response to the estimated passenger demand in 2021 was investigated in 3 different scenarios.

Findings- It is foreseen that the GHYMETRO project, which will be carried out according to the data obtained as a result of simulation analysis under effective capacity conditions (with $95 \%$ and $100 \%$ occupancy rate), can meet $70 \%$ of the total passenger demand at Istanbul Airport in the 1st Scenario. In the scenario 2, which is assumed that the COVID-19 crisis continues, it is observed that there will be $99 \%$ residual capacity in the pessimistic situation, and $72 \%$ residual capacity in optimistic situation. Finally, it is predicted that there will be $43 \%$ residual capacity in the pessimistic situation and $14 \%$ residual capacity in optimistic situation in Scenario 3, where the normalization process is evaluated after the COVID-19 crisis.

Conclusion- Based on these analyses, it can be concluded that COVID-19 crises stroke almost all aviation activities and its related sectors severely so that up-to-date projects should be taken place to carry on their operations.

Keywords: Istanbul Airport, metro capacity, COVID-19 crisis, air transportation, simulation.

JEL Codes: L93, R41, L98

\section{INTRODUCTION}

The air transport industry has been an undisputedly important catalyst of globalization and one of the pillars of today's economy and society. The world economy is now increasingly dependent on air travel, and an increasing share of value is transported by air (Martin, 2009). Unsurprisingly, air traffic has grown steadily both in terms of passengers and transported cargo since the advent of civil aviation. Looking back, world passenger traffic has been around $12 \%$ annually since 1945 ; since 1960 , an annual growth of $9 \%$ has been reported. Air traffic is expected to continue in the future and double in traffic every 12 years (TRKC, 2010).

Today, the interaction between modes of transport is more intense than in the past, and this has led to the emergence of transport integration, common model, and intermodal concepts (EUROCONTROL, 2005). Airports are no longer an exception, now considered as one of the important multi-mode junctions and central nodes in the network. The transport industry places 
great emphasis on research of how to improve the sustainability of the industry through better network integration and the introduction of smoother modes of transport and more optimized systems. Airports, the most vital parts of air transportation, are an important stop in most cities. This situation reveals the necessity of the connections to the airports, primarily the railway (Mahmassani, Chebli, Slaughter, \& Ludders, 2002). Since railways are the most sustainable transport links, there has been a clear political trend to encourage investments at this field (European Commission, 2011). Therefore, the development of efficient railway infrastructures and integration with central transportation nodes such as the airport is an important issue in planning more efficient and sustainable transportation networks. Integration with other modes of transportation is an advantage for all parties, since long-distance transportation by air makes a noticeable difference compared to other models (Barreira, 2012).

In the light of the fact that network between city and airport is essential for more demand, Istanbul Airport is planned to be linked to the city by many means of transportation. Railway connection is one of the most important way to provided sustained transportation to/from the airport since it is not being affected from any traffic jam. Especially in crowded cities, intense traffic may cause long transportation time which leads passenger to lose their enthusiasm while choosing air transportation. Hence, new metro line for new airport is quite necessary. To fill this need Gayrettepe - Istanbul Airport Metro Line (GHYMETRO) is being constructed. With this GHYMETRO line, the integration of the city with important public transport hubs and urban rail system lines will be ensured, so that fast and comfortable access to Istanbul Airport will be provided. With this progress, new questions are lined waiting to be replied. How much will new metro cover the present demand and If COVID-19 crisis or similar crises breaks out, would it be still rational to construct such alternative way to the airport etc. In this study these questions are tried to be answered with actual and estimated data obtained from air transportation companies and aviation authorities.

In this study, the capacity coverage ratio of the Istanbul Airport and the effects of the COVID-19 crisis on the forecasts and investments will be evaluated in line with the number of passengers envisaged in 2021. In addition, different scenarios will be evaluated about the continuation of the crisis and the transition process. Then, the impact of a crisis such as COVID-19 on demand will be examined. Afterwards, the issue of discontinuing, suspending, or canceling the investments made through the estimated passenger demand during the crisis and after the crisis in the normalization process will be discussed. It is aimed with this study that, what authorities should do before and/or during an unexpected event while evaluating development and investment options. Another aim is providing a perspective to make reasonable changes depending on pessimistic and optimistic scenarios.

\section{LITERATURE REVIEW}

Within the scope of the research, the studies on the integration and development between airports and rail systems and their effects on travel times were reviewed. The obtained information emphasizes the importance of simultaneous operation of different modes of transportation to improve the transportation network and reduce the total travel time for both cargo and passengers.

Literature emphasizes that business travelers are less sensitive to ticket fares and they are keen to choose airport which shortens their total travel time wherever leisure travelers looks for cheaper ticket. Moreover, figures show that great majority of air travelers prefer public transportation to access to the airport (Koster, Verhoef, \& Kroes, 2010; Chang, 2013; Akar, 2013; Gokasar \& Gunay, 2016).Integration between transportation means such as high speed rail services, metro, tramway, bus, shuttle services etc. utilizes total carried passenger capacity. Therefore, instead of constructing new infrastructure types, authorities should focus on connecting existing modes in order to keep costs at minimums and utility at maximum (Givoni \& Banister, 2007; Jiang, Timmermans, Chen, Sun, \& Yao, 2019; Givoni \& Chen, 2017). In addition to all transportation facilities, it is clearly seen that since astronomic figures are in question, integration of railway systems and airport must be observed and calculated before coming into operation. Hence, integration models must be designed for all different scenarios and comprehensive analysis should be made with decision support systems from obtained data such as simulation outputs, survey result etc (Obermair \& Glock, 2014; Zografos, Madas, \& Salouras, 2010; Gudmundsson, Cattaneo, \& Redondi, 2020).

Research in methodology has shown that Binary logit (BL), binary panel mixed logit (BPML), generalized binary panel mixed logit (GBPML), goal function modelling (GFM), Auto Regressive Integrated Moving Average - ARIMAX, Principal Component Analysis (PCA) and discrete selection models are commonly used since it is not an isolated and/or single concept to comprehend (Koster, Verhoef, \& Kroes, 2010; Zografos, Madas, \& Salouras, 2010; Gokasar \& Gunay, 2016; Gudmundsson, Cattaneo, \& Redondi, 2020). Therefore, while making a decision about integration of transport types, both internal and external factors should me taken into consideration.

Integration air transportation with other way of transport has so much different result depends on country and region. When the distance between two point is faraway, demand will increase naturally. So that, even small percentage of integration with 
air transportation may provide high benefit (Jiang, Timmermans, Chen, Sun, \& Yao, 2019). Since most part of passengers does not prefer/use private car to access airport, public transportation integration become even more vital for sustainable transportation network (Akar, 2013; Chang, 2013; Gokasar \& Gunay, 2016).

In case of unexpected events, managers and authorities should have alternatives to come up with. Petrol crisis, epidemics etc. have massive effect on air transportation. That is why, investments and developments must be delayed or cancelled provided that undesired global events occur. What authorities should do is, predicting possible healing process and rearrange their plans (Gudmundsson, Cattaneo, \& Redondi, 2020).

The studies in the field are listed in the table below Table 1.

Table 1: Literature Review

\begin{tabular}{|c|c|c|c|}
\hline Reference & Purpose of Study & Methodology & Results and Recommendation \\
\hline $\begin{array}{l}\text { (Givoni \& } \\
\text { Banister, 2007) }\end{array}$ & $\begin{array}{l}\text { Determining the role of } \\
\text { railways in air transportation } \\
\text { in the future. }\end{array}$ & $\begin{array}{l}\text { Railway connections to airports and } \\
\text { relationship between rail and air } \\
\text { transport networks has been } \\
\text { compared. }\end{array}$ & $\begin{array}{l}\text { integration can provide better } \\
\text { utilization of existing air capacity } \\
\text { rather than replicating some high } \\
\text { speed rail routes and services. }\end{array}$ \\
\hline $\begin{array}{l}\text { (Koster, Verhoef, } \\
\text { \& Kroes, 2010) }\end{array}$ & $\begin{array}{l}\text { Analyzing the cost of access } \\
\text { travel time variability for air } \\
\text { passengers. }\end{array}$ & $\begin{array}{l}\text { Binary logit (BL), binary panel mixed } \\
\text { logit (BPML) and the generalized } \\
\text { binary panel mixed logit (GBPML) } \\
\text { model have been applied. }\end{array}$ & $\begin{array}{l}\text { Business travelers are willing to pay } \\
\text { more to relatively shorten travel } \\
\text { time, in part because of its low cost } \\
\text { sensitivity. }\end{array}$ \\
\hline $\begin{array}{l}\text { (Zografos, } \\
\text { Madas, \& } \\
\text { Salouras, 2010) }\end{array}$ & $\begin{array}{l}\text { Establishing a decision } \\
\text { support system for total } \\
\text { airport operations } \\
\text { management and planning. }\end{array}$ & $\begin{array}{l}\text { For the elicitation of decision support } \\
\text { requirements and stakeholders' } \\
\text { preferences, the goal function } \\
\text { modelling (GFM) approach was initially } \\
\text { used. }\end{array}$ & $\begin{array}{l}\text { This system offers a simple, fast, and } \\
\text { useful solution to scenarios that may } \\
\text { cause delays or halts of activities. } \\
\text { Thus, forward-looking scenarios can } \\
\text { be simulated, and more accurate } \\
\text { decisions can be made. }\end{array}$ \\
\hline (Chang, 2013) & $\begin{array}{l}\text { Examining the preferences of } \\
\text { elderly passengers to the } \\
\text { airport }\end{array}$ & $\begin{array}{l}\text { Five-point Likert-scale was used to } \\
\text { reach data. After getting data, } \\
\text { Importance-Performance Analysis } \\
\text { (IPA) is used. }\end{array}$ & $\begin{array}{l}\text { Elderly passengers prefer to be } \\
\text { transported to the airport by private } \\
\text { vehicles instead of public } \\
\text { transportation. }\end{array}$ \\
\hline (Akar, 2013) & $\begin{array}{l}\text { To examine the choice of } \\
\text { modes of transportation to } \\
\text { Port Columbus International } \\
\text { Airport }\end{array}$ & $\begin{array}{l}\text { Principal Component Analysis (PCA) } \\
\text { and Binary logit models have been } \\
\text { applied respectively. }\end{array}$ & $\begin{array}{l}\text { passengers traveling alone or with } \\
\text { few people seem to prefer public } \\
\text { transportation rather than individual } \\
\text { vehicles. Those who prefer public } \\
\text { transportation prefer rail systems } \\
\text { the most after shuttle services. }\end{array}$ \\
\hline $\begin{array}{l}\text { (Obermair \& } \\
\text { Glock, 2014) }\end{array}$ & $\begin{array}{l}\text { A research on the railway } \\
\text { connection of Vienna } \\
\text { International Airport has been } \\
\text { conducted. }\end{array}$ & $\begin{array}{l}\text { Modeling was implemented using the } \\
\text { AnyLogic simulation program. }\end{array}$ & $\begin{array}{l}\text { With this program, a transport } \\
\text { company foresees easily to guess } \\
\text { which train allows transporting } \\
\text { maximum passengers efficiently. }\end{array}$ \\
\hline $\begin{array}{l}\text { (Gokasar \& } \\
\text { Gunay, 2016). }\end{array}$ & $\begin{array}{l}\text { It is aimed to be modelled of } \\
\text { access to airports in Istanbul } \\
\text { in } 2016 .\end{array}$ & $\begin{array}{l}\text { A study was carried out by applying } \\
\text { the discrete selection model. }\end{array}$ & $\begin{array}{l}\text { if public transportation is available at } \\
\text { origin point of passenger, they } \\
\text { prefer public transportation more } \\
\text { intensely. }\end{array}$ \\
\hline $\begin{array}{l}\text { (Givoni \& Chen, } \\
\text { 2017) }\end{array}$ & $\begin{array}{l}\text { Examining the airport-rail } \\
\text { integration level and potential } \\
\text { in Shanghai Hongqiao } \\
\text { Integrated Transport Center. }\end{array}$ & $\begin{array}{l}\text { the Integrated hub model - short-haul } \\
\text { services are provided by the airlines } \\
\text { using the railways (rather than aircraft) } \\
\text { to feed traffic into the airlines' long- } \\
\text { haul services- has been implemented. }\end{array}$ & $\begin{array}{l}\text { Despite the excellent infrastructure, } \\
\text { the actual level of integration is low, } \\
\text { but the potential benefits of this } \\
\text { integration can be enormous. }\end{array}$ \\
\hline $\begin{array}{l}\text { (Jiang, } \\
\text { Timmermans, } \\
\text { Chen, Sun, \& } \\
\text { Yao, 2019). }\end{array}$ & $\begin{array}{l}\text { To discover the determinants } \\
\text { of the airport-rail integration } \\
\text { service in China. }\end{array}$ & $\begin{array}{l}\text { A comparative analysis based on } \\
\text { historical data and specified } \\
\text { preferences was used. }\end{array}$ & $\begin{array}{l}\text { A small increase in the market share } \\
\text { of the airport-railway integration } \\
\text { service provided a significant } \\
\text { increase in the number of } \\
\text { passengers. }\end{array}$ \\
\hline $\begin{array}{l}\text { (Gudmundsson, } \\
\text { Cattaneo, \& } \\
\text { Redondi, 2020) }\end{array}$ & $\begin{array}{l}\text { Predicting the healing process } \\
\text { of air transport after Covid-19. }\end{array}$ & $\begin{array}{l}\text { Auto Regressive Integrated Moving } \\
\text { Average - ARIMAX models are applied } \\
\text { with structural changes. }\end{array}$ & $\begin{array}{l}\text { Although the results obtained differ } \\
\text { across countries, in general, it means } \\
\text { that at the end of } 2023 \text {, air transport } \\
\text { companies will catch up with the } \\
\text { previous situation. }\end{array}$ \\
\hline
\end{tabular}




\section{DATA AND METHODOLOGY}

\subsection{Methodology}

Today, aviation operators use different simulation tools to support decision-making at various levels through the use and evaluation of alternative scenarios (Hafner, 2019; Landau, et al., 2015). In this study, it has been evaluated how Gayrettepe Istanbul New Airport Metro Line (GHY METRO) connection, which is planned to be completed in the middle of 2021, can meet the passenger demand in 3 different scenarios. The AnyLogic 8.5.2 simulation program was used to simulate different scenarios. In the research, a simulation was designed by considering the frequency of the metro, travel time, metro capacity and the number of passengers that can be transported each time. The data required to estimate the transportation of the foreseen passengers in 2021 was taken from the General Directorate of State Airports Authority (DHMi). Information such as the number, capacity and duration of the railway system were obtained from GHYMETRO and METRO iSTANBUL data sharing sources. Different scenarios as transportation some of the passengers other than by rail, increasing the number of voyages during peak hours and the presence of other transportation modes, nevertheless, are not included in the simulation. Since all obtained data is annual, estimations are made by taking the average values into consideration.

To calculate the accurate one-way capacity of each wagon (for 50 passengers) for an hour, tens of simulation have been run. The simulation model shown in Fig.1 was run in perfect condition where no crises or demand-fall occur. After test, the average number which was stated as 939 is used for all different scenarios by multiplying number of wagon and workhours. Figure 1 . shows the transportation time and number of passengers carried to airport.

Since our study works on the metro which has 200 passenger capacity firstly, 939 was multiplied with 4 . Secondly, emerging data was multiplied with 18 which is estimated as daily workhour. Finally, it is figured out that, two-way (between city and airport) and 200 passenger capacity metro working 18 hours can carry approximately 135,216 passenger a day.

Figure 1: Model with time and number of passengers carried for one-way 50 Passengers

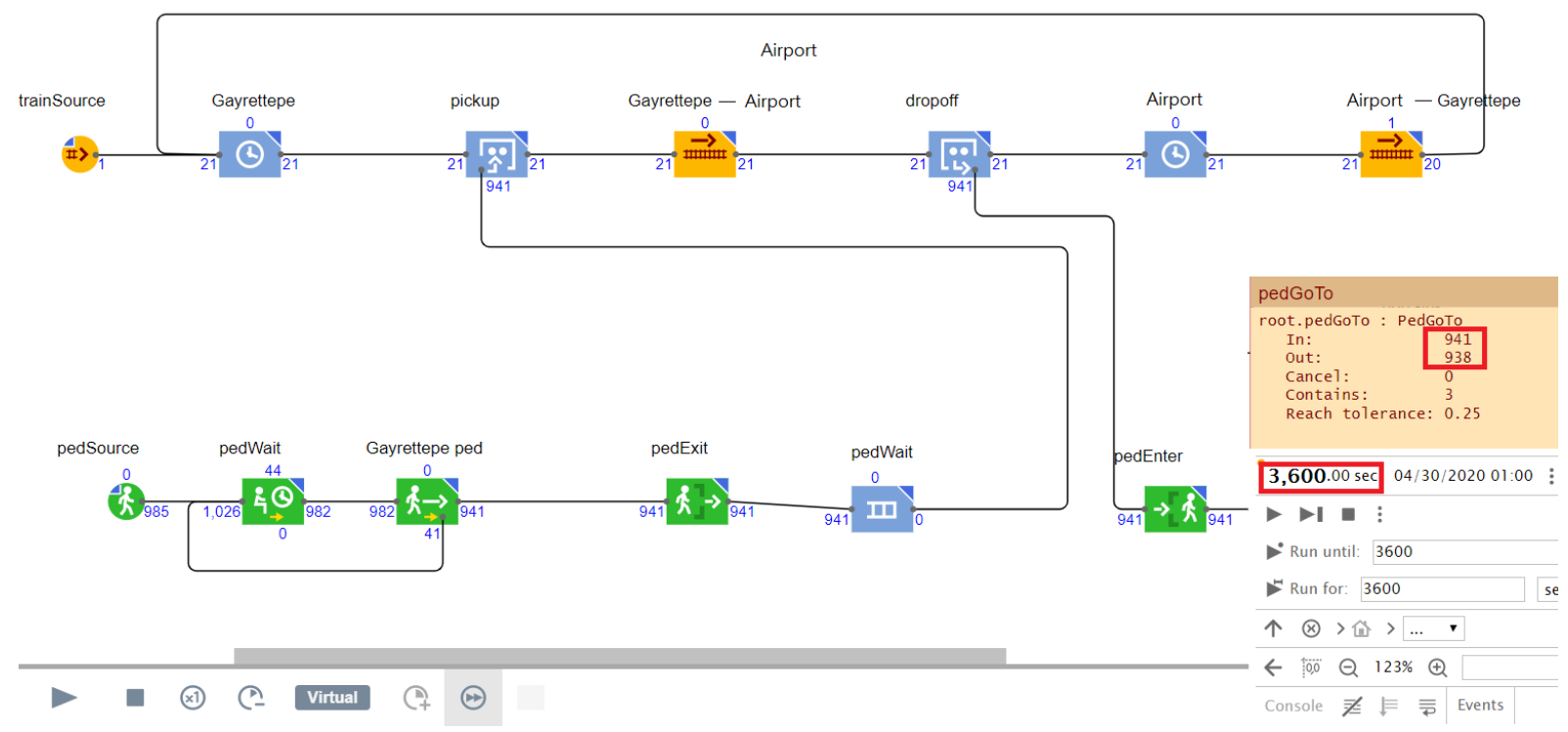

\subsection{Simulation Model}

The number of incoming and outgoing passengers in 2021, which is the first of the estimated data to be used in the implementation section, is assumed to be 70 million for 2021, according to the increase rate of the past 3 years (approximately 2\%). The daily passenger carrying capacity of the GHY METRO, was accepted as 70,000 in the secondary data sources given by the authorities. It was also assumed that the travel time of the line would be 32 minutes on average and transportation to the airport would be provided every 3 minutes. It is assumed that the metro service operates on average 18 hours a day and transports an average of 200 passengers each time to the airport and / or city. The percentages used in the scenarios were determined by the experts' outlook in the aviation field and the feasible restricted forecasts made by the authorities. In the study, different future scenarios were determined in line with the scarce data and expert comments. Thus, 
hypothetical expert opinions on future data and information which is not approved by official authorities were considered as a limitation in the study. The table below shows the percentages to be used in 3 different scenarios (table2).

Table 2: Percentages to be used in 3 different scenarios

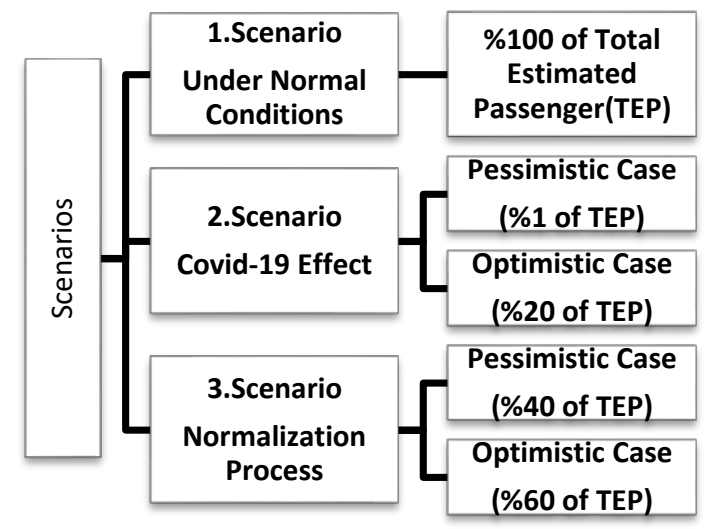

The estimated number of passengers to be transported per day (if a total of 70 million passengers are distributed per day on average) used in Scenario 1 is 192,000. The situation where the metro line operates at full capacity (100\% efficient use) is simulated. In this case, it is seen that it is possible to transport an average of 135,216 people per day (total daily round trip).

In Scenario 2, the situation is simulated in which the COVID-19 crisis or similar crisis environment continues, and all interaction and travel opportunities are extremely limited. It is assumed that the drug to be developed for the treatment of COVID-19 crisis will be widely available in the market in late 2021 or early 2022 (Gudmundsson, Cattaneo, \& Redondi, 2020). Therefore, there is both extreme concern by the passengers and strict restrictions by the authorities. In this scenario, two different situations - optimistic and pessimistic- are evaluated. In the pessimistic scenario, a situation is simulated in which almost no scheduled flight is allowed except for compulsory flights. This means that the total estimated number has decreased by $99 \%$ and the total number of passengers carried per day is reduced to 1100 passengers. In the optimistic scenario, the situation in which the crisis environment continues but certain scheduled flights are allowed, and the low level of travel activity is on. In this case, it is assumed that 38.350 passengers, which represent only $20 \%$ of the total estimated number of passengers, are carried.

A scenario is simulated in Scenario 3 where the COVID-19 crisis or a similar crisis environment is over, and the normalization process takes place under the control of authorities' precaution. In this scenario, two different situations are evaluated, named optimistic and pessimistic. In the pessimistic scenario, a situation is simulated in which the rules are a bit stricter and travel is significantly restricted without an acceptable reason.

\subsection{Data Analysis}

All the estimated and actual data obtained were analyzed separately for all scenarios using the AnyLogic Simulation Program. Estimated demands are determined according to each scenario in the program and the rates of meeting the demand are revealed with the simulation data obtained.

In the first scenario, total handled passengers are assumed as 192,000 dailies. In the full capacity metro simulation of 135,216 of the total passengers can be transported with the upcoming rail system. This figure corresponds to $70.43 \%$, an important part of the passenger needs to be carried daily, in line with the information accepted in the simulation model (Table 3.). In this scenario, the crisis cases that cause all direct and indirect aviation companies to come to a halt have been consciously ignored in future predictions. Otherwise, long-term plans based on the short-term increases and decreases instead of average data by years may have undesired erroneous results.

In the second scenario, the situation in which the COVID-19 crisis or a similar crisis environment continues is discussed. In the light of the analysis data, when the pessimistic situation in which the flights drop to $1 \%$ level is simulated, $99.98 \%$ capacity surplus is envisaged. When the optimistic situation, where certain strict restrictions are eliminated and the total demand is assumed to be around $20 \%$, is simulated, an overcapacity of $71.63 \%$ is expected (Table 3.).

Within the scope of the third scenario, the situation in which the crisis environment has ended, and the normalization process has been taken into consideration. Two possibilities are simulated, pessimistic and optimistic, to determine the potential 
range based on estimates and expert opinions. When the pessimistic situation, which is assumed to be $40 \%$ of the total demand, where normalization begins but the restrictions continue by the authorities, is simulated, an overcapacity of $43.0 \%$ is envisaged. When the optimistic situation, which is assumed to be stretched with normalization, and where $60 \%$ of the total demand is supposed to travel, is simulated, a capacity surplus of $14.80 \%$ is expected (Table 3.).

Table 3: Demand Coverage Rates of Scenarios

\begin{tabular}{|c|c|c|c|c|}
\hline & $\begin{array}{l}\text { Estimated Number } \\
\text { of Passenger (Daily) }\end{array}$ & $\begin{array}{l}\text { Estimated Metro } \\
\text { Capacity (Daily) }\end{array}$ & $\begin{array}{r}\text { Demand Coverage } \\
\text { Rate (Daily) } \\
\end{array}$ & $\begin{array}{l}\text { Unused Metro } \\
\text { Capacity (Daily) }\end{array}$ \\
\hline $\begin{array}{l}\text { 1.st Scenario (\%100 of Estimated Number of } \\
\text { Passenger) }\end{array}$ & 192000 & \multirow{5}{*}{$\begin{array}{c}135216 \text { passengers } \\
\text { (\%100 Efficiency is } \\
\text { assumed) }\end{array}$} & $70,43 \%$ & $\% 0$ \\
\hline 2.nd Scenario (pessimistic case) (\%1 of ENP) & 1100 & & $100 \%$ & $99,9 \%$ \\
\hline 2.nd Scenario (optimistic case) (\%20 of ENP) & 38350 & & $100 \%$ & $71,63 \%$ \\
\hline 3.rd Scenario (pessimistic case) (\%40 of ENP) & 76800 & & $100 \%$ & $43 \%$ \\
\hline 3.rd Scenario (optimistic case) (\%60 of ENP) & 115200 & & $100 \%$ & $14,80 \%$ \\
\hline
\end{tabular}

\section{FINDINGS AND DISCUSSIONS}

In three different scenarios made with the help of Anylogic Simulation Program, it was tried to foresee to what extent the GHYMETRO line will meet and/or exceed the total passenger transport demand at Istanbul Airport. In the first scenario, normal conditions are taken into consideration and it is assumed that the number of passengers will increase in line with the historical data announced by ICAO and DHMI. In addition, the data in the first scenario also parallels the data accepted in the subway work. In addition, it is stated that the expeditions and capacity can be increased to meet the passenger demand if needed. The data obtained after the simulation study show that $70.43 \%$ of the passengers already carried by bus and car can be carried by rail systems. When this figure is viewed in terms of city traffic, it seems possible that bus and car density will decrease significantly. In addition, the absence of any traffic on the metro line is expected to shorten the time for passengers to travel to and from the airport. Another advantage of the subway service is the decrease in the rate of individual vehicles and carbon monoxide emission. This will help reduce air pollution.

The second scenario is simulated to present the figures that will arise when faced with a situation that would largely halt the activities of the aviation industry, such as the COVID-19 crisis, which particularly affected the world in the first quarter of 2020. In the pessimistic situation simulation, which was based on when the crisis was experienced at the highest level, an excess capacity of $99.9 \%$ emerged. Although unacceptable, these results could be recorded in times of crisis, e.g. in April and May 2020 (DHMi, 2020). It shows that no investment should be made in such a situation. On the contrary, ongoing investments should be canceled or stopped. But especially sudden changes should be ignored when making such decisions. Otherwise, it may not be possible to meet the demand encountered after normalization. In the optimistic situation simulation, the process in which the mandatory restrictions that cause the number of trips to be reduced are considered. Although not as pessimistic, an overcapacity of $71.63 \%$ is anticipated. In such a case, even if the long-term investments are not canceled, they can be delayed due to the inconvenience state of normalization process. Otherwise, in this process, where revenues are at very low level, costs may put businesses under greater difficulties.

Situations that are tried to be simulated in the third scenario were carried out to predict a precautionary stage before the emergence of any extraordinary situation or the situation that will occur when the normalization stage is passed at the end of this period. In the pessimistic situation scenario, a capacity surplus of $43.0 \%$ is predicted to occur during the post-crisis normalization process. While simulating this process, two states have been considered. First one is that the authorities lifted the measures only in the limited process during the normalization process and secondly, suspicious, and abstaining attitude of passengers using air transportation. In this case, it is considered as an appropriate decision that to postpone the investment until at least one of two states has lost its effect. In the optimistic scenario, a situation simulated in which the abstaining attitudes of the passengers has been decreased, crisis has been significantly overcome psychologically and sociologically, and the authorities have greatly stretched the rules. As a result of the analysis, it is predicted that an excess capacity of $14,80 \%$ will occur. In such a case, tendency of the process should be evaluated by the experts over again, and if the picture gives a positive impression, the metro line works should continue as planned. However, if the estimations are made that the normalization process will be prolonged, it may be considered an appropriate strategy to delay or slow down the plans in parallel with this period. 


\section{CONCLUSION}

Air transport can have a much wider network when supported by other modes of transport. It is extremely important to integrate multiple transportation methods to shorten the total journey time. All these works should be carried out in line with potential demand. Crisis periods are processes that should be managed cautiously for the aviation sector, which is directly affected by most global events. The COVID-19 crisis that emerged in the first quarter of 2020 not only brought air transportation to a halt, but also significantly affected future investment plans. Since different scenarios are determined in accordance with the data and expert comments currently available, it is likely that there may be some changes in figures and rates in future studies.

In the first scenario where the crises are ignored, the expected normal demand is expected to be met by $70.43 \%$ with the metro line to be built. This is expected to significantly reduce urban-airport road traffic. Thus, direct contribution will be made to the reduction of air pollution. In addition, the journey time of the passenger from the city to the airport will decrease and become more prominent. Total journey time will be shortened.

In the pessimistic situation simulation of the second scenario, in which crisis periods are simulated, no alternative is anticipated for any indirect or direct aviation business, other than bypassing the process immediately. Because a business policy that is arranged according to the moments of crisis will lose its validity in post-crisis situations. As a result of the optimistic situation analysis in the second scenario, long-term investments can be stopped by suspension or postponement. In this way, it can be ensured that scarce assets are used for more vital items such as personnel wages in these situations where incomes are minimized.

In the pessimistic situation simulation of the third scenario in which the normalization process is simulated, the emergence of an overcapacity of $43.0 \%$ indicates that the process has not yet returned to normal. In such a case, when deciding to stop or cancel an investment, two things or at least one of both must be taken into consideration: (1) the authorities that have a power to stretch the restrictions, (2) abstaining the approach of passengers and employees. Otherwise, it may not be possible to return the expenditures in the short term. In the optimistic situation simulation of the third scenario, an analysis was carried out, assuming that authority restrictions have been stretched, and the abstaining approaches of passengers and employees have turned to normal, or at least one of them occurred. In this case, only an excess capacity of $14.80 \%$ is foreseen. In accordance with positive rise forecast, short-term delays or no-delays can be made to investments and plans upon. Thus, at the end of normalization, it will be possible to provide sufficient service infrastructure to meet the targeted demand.

\section{REFERENCES}

Akar, G. (2013). Ground access to airports, case study: Port Columbus International Airport. Journal of Air Transport Management, $25-31$.

Barreira, A. (2012). Dissertation to obtain the Master of Science Degree in Civil Engineering: Technical University of Lisbon.

Chang, Y.-C. (2013). Factors affecting airport access mode choice for elderly air passengers. Transportation Research Part E, 105-112.

DHMi. (2020). 2020 NISAN, MAYIS AYI YOLCU TRAFIĞi. ANKARA: DHMi.

EUROCONTROL. (2005). Potential airport intermodality development, CARE II: MODAIR Measure and development of intermodality at airport, version 1.1. BRUSSEL: EUROCONTROL.

European Commission. (2011). Roadmap to a Single Euro pean Transport Area e Towards a competitive and resource efficient transport system. COM (2011) 144 final.

Givoni, M., \& Banister, D. (2007). Role of the Railways in the Future of Air Transport. Transportation Planning and Technology, 95-112.

Givoni, M., \& Chen, X. (2017). Airline and railway disintegration in China: the case of Shanghai Hongqiao Integrated Transport Hub. The International Journal of Transportation Research, 202-214.

Gokasar, İ., \& Gunay, G. (2016). Mode choice behavior modeling of ground access to airports: A case study in Istanbul, Turkey. Journal of Air Transport Management, 1-7.

Gudmundsson, S. V., Cattaneo, M., \& Redondi, R. (2020). Forecasting recovery time in air transport markets in the presence of large economic shocks: COVID-19. France: Toulouse Business School.

Hafner, F. B. (2019). Simulation Options for Airport Planning. Washington: National Academy of Sciences.

Jiang, Y., Timmermans, H., Chen, C., Sun, J., \& Yao, B. (2019). Determinants of air-rail integration service of Shijiazhuang airport, China: analysis of historical data and stated preferences. Transportmetrica B: Transport Dynamics, 1572-1587.

Koster, P., Verhoef, P. E., \& Kroes, E. (2010). Travel Time Variability and Airport Accessibility. Amsterdam: Paper No. TI 2010-061/3,. 
Landau, S., Weisbrod, G., Gosling, G., Williges, C., Pumphrey, M., \& Fowler, M. (2015). Passenger Value of Time, Benefit-Cost Analysis and Airport Capital Investment Decisions. Washington: National Academy of Sciences.

Mahmassani, H. S., Chebli, H., Slaughter, K., \& Ludders, J. F. (2002). Assessment of Intermodal Strategies for Airport Access. Austin: Research Project 0-1849.

Martin, S. C. (2009). Passenger air service development techniques (No. Project 03-08).

Obermair, M., \& Glock, B. (2014). Agent-based Simulation of the Railway Connection from and to the Vienna International Airport . Simulation Notes Europe, 123-126.

TRKC. (2010). Air Transport - Thematic Research Summary. Transport Research Knowledge Centre.

Zografos, K. G., Madas, M. A., \& Salouras, Y. (2013). A decision support system for total airport operations management and planning. Journal of Advanced Transportation, 47(2), 170-189. 